\title{
Interventions to Reduce Antibiotic Prescribing in LMICs: A Scoping Review of Evidence from Human and Animal Health Systems
}

\author{
Annie Wilkinson *, Ayako Ebata and Hayley MacGregor \\ Institute of Development Studies, University of Sussex, Brighton BN1 NRE, UK; a.ebata@ids.ac.uk (A.E.); \\ h.macgregor@ids.ac.uk (H.M.) \\ * Correspondence: a.wilkinson@ids.ac.uk; Tel.: +44-(0)1273-915-602
}

Received: 1 November 2018; Accepted: 18 December 2018; Published: 22 December 2018

\begin{abstract}
This review identifies evidence on supply-side interventions to change the practices of antibiotic prescribers and gatekeepers in low- and middle-income countries (LMICs). A total of 102 studies met the inclusion criteria, of which 70 studies evaluated interventions and 32 provided insight into prescribing contexts. All intervention studies were from human healthcare settings, none were from animal health. Only one context study examined antibiotic use in animal health. The evidence base is uneven, with the strongest evidence on knowledge and stewardship interventions. The review found that multiplex interventions that combine different strategies to influence behaviour tend to have a higher success rate than interventions based on single strategies. Evidence on prescribing contexts highlights interacting influences including health system quality, education, perceptions of patient demand, bureaucratic processes, profit, competition, and cultures of care. Most interventions took place within one health setting. Very few studies targeted interventions across different kinds of providers and settings. Interventions in hospitals were the most commonly evaluated. There is much less evidence on private and informal private providers who play a major role in drug distribution in LMICs. There were no interventions involving drug detailers or the pharmaceutical companies despite their prominent role in the contextual studies.
\end{abstract}

Keywords: antibiotic resistance; antibiotic prescribing; antibiotic use; antibiotic stewardship

\section{Introduction}

Globally, antibiotic use is increasing, up 65\% between 2000 and 2015 [1]. The majority of this increase has been caused by rapid expansion of use in low- and middle-income countries (LMICs). Consumption rates in many LMICs are catching up with higher-income countries [1] but usage is often unnecessary due to lack of supportive regulation and widespread informal use [2]. While access to antibiotics is of clear public health benefit, the inappropriate use of antibiotics is a major driver of antibiotic resistance [3] and requires urgent attention. To inform context-appropriate policy in LMICs, we conducted a review of supply side interventions and their impact on unnecessary and inappropriate use of antibiotics in human and animal health systems. The aim was to determine the evidence base for changing the practices of antibiotic prescribers and gatekeepers in LMICs.

Previous systematic reviews have found evidence to support a range of effective and safe interventions to reduce antibiotic prescribing in human health settings. Interventions that combine restrictive and enabling policies have shown better results [4]. Interventions that are interactive and multi-faceted have stronger effects, for example education with feedback and monitoring mechanisms [5,6]. However, the majority of studies included in these reviews are from high-income countries, and within that a limited range of settings (e.g., in-patient prescribing) and methods. 
One review [6] looked specifically for evidence on doctor's prescribing in primary care in upper middle-income countries. However, their review only included eight studies and the authors noted that the quality of evidence was limited. We are not aware of any reviews of prescribing interventions in animal health settings. Taken together, these reviews have found encouraging results but there are questions about how generalizable they are beyond the specific targeted groups (e.g., doctors) and homogenous prescribing contexts (e.g., formal providers in relatively well organised human health systems in high-income countries). LMICs, as defined by World Bank, include a variety of health system arrangements, which makes generalizations difficult. However, in many, the human and animal healthcare contexts can be described as "pluralistic", where people consult a variety of public, private, traditional, biomedical, formal and informal providers, and where the capacity of governments to regulate these providers is variable, and is increasingly recognised as a major concern [7]. Effective action is complicated by high rates of infection due to poor preventative public health combined with inconsistent and inequitable access to essential medicines. As such, research on LMICs interventions and contexts is urgently needed and is the focus of this review.

The monitoring of unintended consequences requires particular attention as the supply and distribution of antibiotics has the potential to include competing objectives and is sensitive to interventions not specifically targeting antibiotic use. For example, the use of rapid diagnostic tests to improve malaria diagnosis has led to an increase in antibiotic use in some settings [8,9].

The review set out to answer the following questions (for human and animal health systems):

- What supply-side interventions have been tried in LMICs to reduce inappropriate antibiotic prescribing and sale?

- Where have interventions been implemented e.g., country and kind of health care settings?

- Which kinds of interventions have shown promise in reducing inappropriate prescribing?

- What information exists on the contexts of interventions and attempts to influence antibiotic use and prescribing?

\section{Methods}

We carried out a scoping review to provide an overview of the evidence base, as opposed to narrowing down to aggregate sub-sets of evidence as in a systematic review [10,11]. In addition to quantitative evaluations of interventions, we include qualitative studies describing the contexts of interventions to enhance understanding of the drivers of prescribing and barriers to reducing prescribing. We carried the review out in five stages: (1) identifying the research question; (2) identifying relevant studies; (3) study selection; (4) charting the data; and (5) collating, summarising and reporting the results [12].

\subsection{Search Strategy}

We conducted a systematic search guided by a combination of the PICO (Population, Intervention, Comparison, and Outcome) and PICo (Population/Problem, Interest, Context) approach. Full parameters are in Appendix A. PICO is usually used for quantitative reviews while PICo is used for qualitative reviews. As we were interested in both human and animal antibiotic prescribing, we looked for studies concerning people who supply antibiotics to sick people or animals, e.g., doctors and other healthcare prescribers, drug sellers, informal doctors, pharmacists, community health workers, veterinarians, farmers, and community animal health workers. We looked for any intervention aiming to influence the prescribing or sale of antibiotics (formal and informal), e.g., communication and education, stewardship programmes, treatment algorithms, delayed treatment, alternative treatments, incentives, pricing, packaging, legislation, and peer or community oversight. Outcomes of interest were measured improvement in antibiotic supply (e.g., reduction in unnecessary antibiotic prescriptions and sales, health worker adherence to guidelines, etc.), as well as reported changes in knowledge and attitudes around antibiotic prescribing, health outcomes (improved, unaffected, or adverse), and 
unintended consequences. Qualitative analysis of the contexts of interventions were also of interest, e.g., implementation of a new policy and descriptions of attempts to influence prescribing.

To identify research in both the biological and social sciences, we searched MEDLINE, SCOPUS and the Cochrane database of clinical trials. We also searched the 3ie database of impact evaluations and the World Organisation for Animal Health (OIE) database. Search terms are included in Appendix B. Table 1 contains the search results for each database searched. Time and resource constraints meant we limited the date range to studies published during 2000-2017. A number of reviews already covered publications before this cut off [4-6], and most studies were published post-2000, so we anticipated the effect of the limitation to be minimal

Table 1. Search results.

\begin{tabular}{cc}
\hline Database & Result \\
\hline Scopus & 20,083 \\
Cochrane Central Register of Controlled Trials (CENTRAL) & 3823 \\
3ie Impact Evaluations & 26 \\
World Organisation for Animal Health (OIE) & 0 \\
Total & 32,066 \\
Total after duplicates removed & 17,716 \\
Total 2000-2017 & 15,142 \\
\hline
\end{tabular}

\subsection{Study Selection}

Two research assistants reviewed the abstracts using the pre-defined inclusion and exclusion criteria below. Borderline studies were discussed within the team. Table 2 shows the number of studies included and excluded at each stage of the review process. From the initial figure of 15,142 search results, the review includes 102 studies. Studies of interventions and intervention contexts were separated out.

Inclusion criteria:

1. Reports on an intervention aiming to influence the prescribing and sale of antibiotics (formal and informal), including the use of antibiotics to treat existing and suspected infections or to prevent infection (e.g., antibiotic prophylaxis)

2. Any healthcare setting in a LMIC country

3. Outcomes:

- Externally measured change in antibiotic use/sale/prescribing

- Externally measured change in knowledge and attitudes around antibiotic use

- Self-reported change in antibiotic use/sale/prescribing

- Self-reported change in knowledge and attitudes around antibiotic use

- Observed change in the quality of antibiotics prescribed/sold

Or for "context studies"

- Studies that describe the contextual factors that influenced the effectiveness of interventions

Exclusion criteria:

- Studies of other ways of addressing antibiotic resistance, e.g., hygiene and infection and prevention control such as vaccines, etc.

- $\quad$ Studies assessing adherence to antibiotics or medicine

- Studies of environmental transmission of antibiotics and antibiotic resistance

- Studies targeting other antimicrobials, and not targeting antibiotic use 
- $\quad$ Studies reporting on/intervening in patient demand for antibiotics and self-use

- Studies evaluating effectiveness of antibiotic treatment in clinical care, e.g., comparing different treatments or ways of administering antibiotics, and reporting on clinical outcomes.

- For "context studies", those studies that only described the context and not the implementation or outcome of an intervention, e.g., a situation analysis

We carried out a detailed data extraction on the remaining 102 studies. For the 32 context studies, we extracted qualitative data summarising their findings, and indicating the setting. For the 70 intervention studies, we extracted descriptive information about the setting, intervention design and implementation, study design, the author's assessment of impact and our own.

Table 2. Selection process.

\begin{tabular}{cc}
\hline \multicolumn{1}{c}{ Stages } \\
\hline Abstract review \\
Excluded (did not meet inclusion criteria) & 15,142 \\
Included- & 14,734 \\
Full text review & 408 \\
\hline Excluded—did not meet inclusion criteria on review & 408 \\
Duplicates (e.g., studies reporting same data) & 289 \\
Full text not available/not in English & 13 \\
\hline Included-context studies & 32 \\
Included-intervention studies & 70 \\
Total—context and intervention & 102 \\
\hline
\end{tabular}

We looked at intervention effectiveness in more detail in a subset of studies $(n=41)$. Studies that contained adequate information to assess effectiveness were included in this analysis. Two researchers assessed studies for inclusion. Our assessment was based on the extent to which studies contained complete information about the intervention and study design and thus whether necessary information was available and how much confidence we had in their results (e.g., sample sizes, $p$-values, primary outcomes, descriptions of the intervention, and identification of setting). Studies that comprehensively discussed their methods and outcomes, and reported strategies to minimize estimation bias and limitations were included. Studies were excluded if they were missing key study design or analysis information such as the selection and measurement of outcomes, sample sizes, or p-values. Those studies that interpreted results incorrectly or employed inconsistent methods for data collection without justification or explanation were also excluded.

\section{Results}

We present summary statistics of the intervention studies included in the review. Table 3 shows the number of studies included from each country. The largest number of studies are from China ( 25 out of 70 studies), followed by India (6 studies). The high number of studies in China may be in response to the major health reforms that took place there, e.g., in 2009, which saw the implementation of Essential Medicine Lists, and, during 2011-2013, when there was a national campaign on improving the use of antibacterial drugs. There are two cross-country studies-one in Brazil and Mexico, and the other in Vietnam and Thailand. The rest of the studies were conducted in a single-country setting. 
Table 3. Country settings.

\begin{tabular}{|c|c|}
\hline \multicolumn{2}{|c|}{ Country, by World Health Organisation Region } \\
\hline African region & 15 \\
\hline Kenya & 3 \\
\hline Mali & 1 \\
\hline Malawi & 1 \\
\hline Nigeria & 3 \\
\hline South Africa & 2 \\
\hline Sudan & 2 \\
\hline Tanzania & 3 \\
\hline Region of the Americas & 5 \\
\hline Argentina & 1 \\
\hline Brazil & 2 \\
\hline Brazil and Mexico & 1 \\
\hline French Guiana & 1 \\
\hline European region & 7 \\
\hline Republic of Srpska, Bosnia and Herzegovina & 1 \\
\hline Serbia & 2 \\
\hline Turkey & 4 \\
\hline Eastern Mediterranean region & 3 \\
\hline Pakistan & 1 \\
\hline Iran & 2 \\
\hline South-East Asian region & 13 \\
\hline India & 6 \\
\hline Indonesia & 1 \\
\hline Nepal & 3 \\
\hline Thailand & 2 \\
\hline Thailand and Vietnam & 1 \\
\hline Western Pacific Region & 27 \\
\hline China & 25 \\
\hline Vietnam & 2 \\
\hline Total & 70 \\
\hline
\end{tabular}

\subsection{Intervention Settings}

We found no interventions addressing antibiotic prescribing in animal health. All intervention studies were from human healthcare settings. The overwhelming majority of the reviewed studies evaluated interventions at public prescribing facilities rather than private (see Figure 1). This trend is particularly pronounced among studies conducted in primary care settings, where 15 out of 22 studies examined the public sector. The exception was for pharmacies where seven out of nine studies were conducted in the private sector. This is likely because pharmacies and drug shops are usually private enterprises. In the hospital settings, 16 and 4 studies were conducted in public and private hospitals, respectively, while in the remaining 16 it is unclear. This was due to the fact that studies mentioned hospitals' names but we were unable to judge whether the hospitals concerned are public or private from available sources. Three other studies are not included in the figures: two were from mixed public and private sector settings, and one was not clear. 


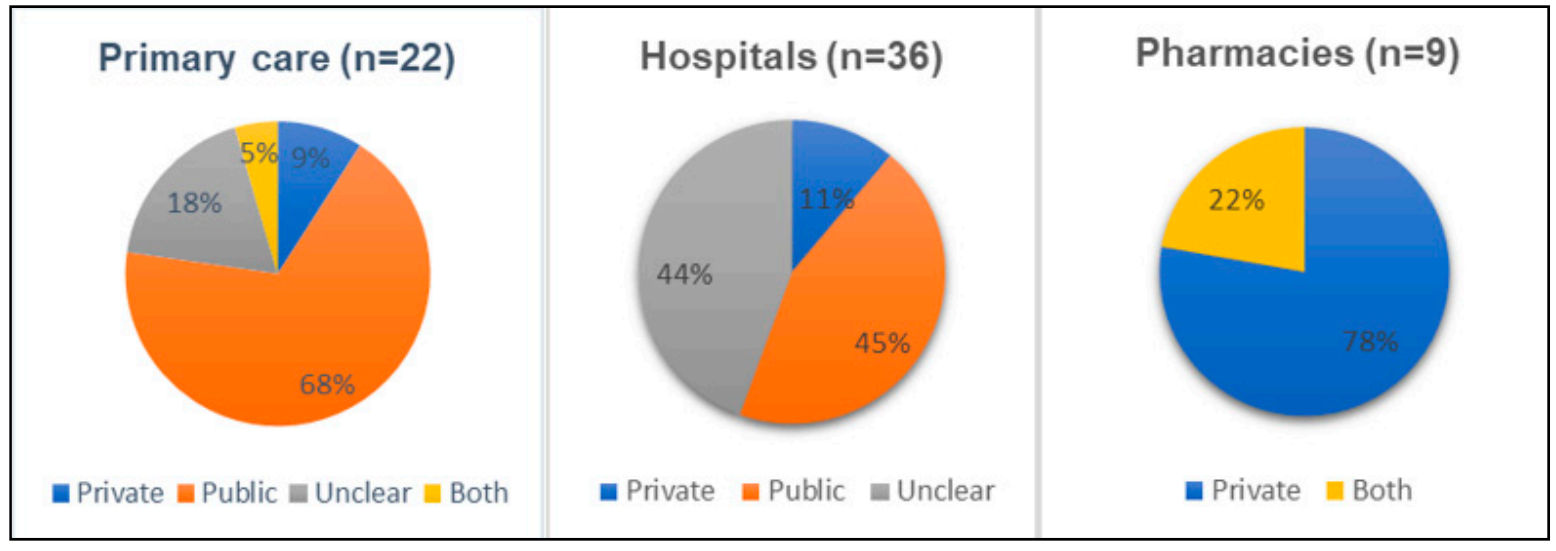

Figure 1. Sector where intervention was tested, by type of health setting.

There was also a majority of studies from urban areas, as shown in Figure 2. In total, 41 out of 70 studies looked at interventions in urban areas. In particular, studies conducted at hospitals and primary care mostly evaluated urban settings. Two of the studies carried out in mixed health care settings were from rural areas, while the remaining one study addressed both rural and urban areas.

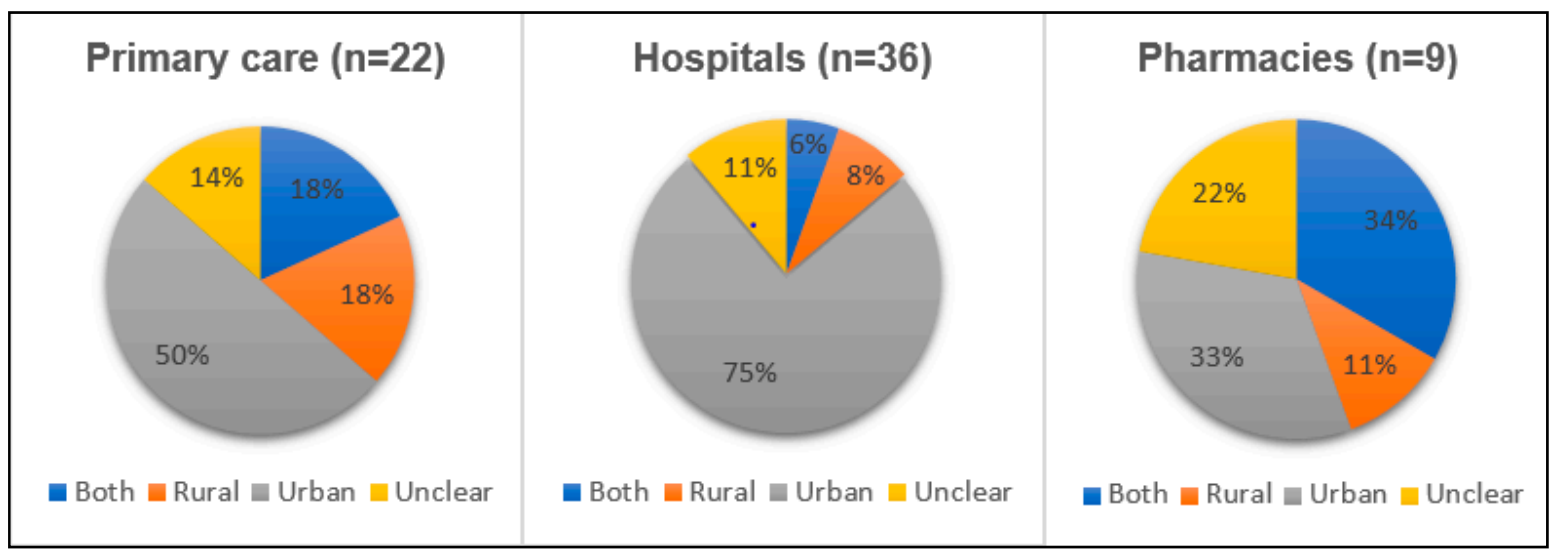

Figure 2. Location (urban or rural) where intervention was tried, by type of health setting.

\subsection{Types of Intervention}

Table 4 presents the types of intervention conducted in different settings in a "gap map" format. Interventions were classified into six broad categories: norms and standards, knowledge interventions, decision support, supply chain, economic, and organisational/management systems. Blank cells indicate that we found no evidence of an intervention being evaluated in that setting. The majority of interventions have only been studied 1-3 times, and often in only one type of setting. The evidence base is uneven, for example, there are 35 hospital-based studies and only nine in pharmacies. Only educational interventions and the essential medicine policy have been evaluated in all settings.

Table 4 reveals a number of gaps in the evidence base though it should be noted that not all forms of intervention are as relevant for each setting. "Audit/Feedback" and "Stewardship Programme" are most often implemented in hospitals in comparison to other settings. This might reflect the ease of monitoring and management in hospital settings, which are arguably more "closed", as well as the availability of expertise (e.g., infectious disease specialists) to perform key supportive roles. All five studies conducted on essential medicines policy in primary care setting come from China where there was major national policy reform. Although essential medicine policies are used widely, caution is needed when considering the generalisability of those studies that report on a specific policy moment and context. 
Table 4. Kinds of intervention, by setting.

\begin{tabular}{|c|c|c|c|c|c|}
\hline Type of Intervention & Hospital & Primary Care & Pharmacies & Mixed Settings & Total \\
\hline \multicolumn{6}{|c|}{ Norms and standards (formal and informal) } \\
\hline Accreditation & & & 1 & & 1 \\
\hline Guidelines & 3 & & & & 3 \\
\hline Public reporting & & 4 & & & 4 \\
\hline \multirow{2}{*}{$\begin{array}{l}\text { Restrict over-the-counter sales } \\
\text { Prescription control }\end{array}$} & & & 2 & & 2 \\
\hline & 1 & & & & 1 \\
\hline \multicolumn{6}{|c|}{ Knowledge } \\
\hline Audit/Feedback & 8 & 2 & & & 10 \\
\hline Education & 2 & 3 & 2 & 2 & 9 \\
\hline \multirow{3}{*}{$\begin{array}{c}\text { Education/Feedback } \\
\text { Education/Feedback/Regulation } \\
\text { Information }\end{array}$} & 3 & 2 & & & 5 \\
\hline & & & 2 & & 2 \\
\hline & 1 & & & & 1 \\
\hline \multicolumn{6}{|c|}{ Decision support } \\
\hline Algorithms & 1 & \multirow[t]{2}{*}{2} & & & 3 \\
\hline Diagnostics & 2 & & & 1 & 3 \\
\hline \multicolumn{6}{|c|}{ Supply chain } \\
\hline \multirow{2}{*}{$\begin{array}{c}\text { Decentralisation of Supply } \\
\text { Drug Delivery }\end{array}$} & & \multirow[t]{2}{*}{1} & & & 1 \\
\hline & 1 & & & & 1 \\
\hline \multicolumn{6}{|c|}{ Economic } \\
\hline Financial incentives & & 1 & & & 1 \\
\hline Pricing strategy & & 1 & & & 1 \\
\hline Health Insurance & 2 & 1 & & & 3 \\
\hline \multicolumn{6}{|c|}{ Organisational/management systems } \\
\hline Essential Medicine Policy & 2 & 5 & 1 & & 8 \\
\hline Stewardship Programme & 10 & & 1 & & 11 \\
\hline Total & 36 & 22 & 9 & 3 & 70 \\
\hline
\end{tabular}

\subsection{Intervention Impact}

We examined impact in a subset of 41 studies (out of 70), selected on the basis of their reporting completeness. Studies were classified as having positive, negative, mixed, or no effect, on the basis of whether they reported improved or deteriorated prescribing rates, a combination, or no change, respectively. Studies reporting decreases in antibiotic prescribing or increased adherence to appropriate guidelines (e.g., choice of antibiotic, timing, dose, and duration of treatment) were classified as positive. Studies reporting increased antibiotic prescribing rates or decreased adherence to guidelines (e.g., increased inappropriate antibiotic use, and use of restricted antibiotics) were classified as negative. Table 5 shows the number of studies reporting each category of impact for each type of intervention.

Twenty-one studies show positive effects of the interventions, thirteen studies document mixed effects, three studies show no effects and four studies indicate negative effects. Studies that had mixed results were those that reported both positive and negative impacts on different prescribing indicators and thus could not be categorised as wholly positive or negative. It should be noted that sometimes this may reflect more complex analysis than the studies reporting positive (or negative) results. The higher number of studies reporting positive or mixed results than negative or no results may be indicative of publication bias. Table 5 includes all intervention types identified by the review so there are some complete rows with no studies, e.g., supply chain interventions where the evidence was found and included in Table 4, but excluded here because of reporting deficiencies.

Overall the evidence base is limited. Results are scattered and number of studies in each category of result and intervention type is small; four being the maximum number of studies reporting positive or mixed results for any intervention type. Out of the studies with positive results, the strongest evidence is clustered around knowledge interventions, and there are four studies for audit/feedback interventions and four for education/feedback interventions. Audit/feedback studies are those which introduced primarily audit interventions (e.g., reviews of prescribing patterns according to guidelines) 
combined with feedback mechanisms (e.g., meetings and reports). Education/feedback studies are those which introduced educational interventions (e.g., training sessions or courses and role play) combined with feedback (e.g., meetings and group discussion). There are five positive evaluations of stewardship interventions. Stewardship studies are those which combined policy review and change (e.g., new targets, development of new guidelines, and incentives/disincentives), the creation of antimicrobial/antibiotic resistance committees or working groups, education, audit and monitoring. Out of studies reporting mixed results, four studies evaluated essential medicine policies as well as public reporting (e.g., monitoring prescribing patterns and posting these publicly in/around health settings). Studies documenting no or negative effects evaluated accreditation, diagnostics, essential medicines policy, education, health insurance, and pricing intervention. More details of intervention types are in Appendix C.

Table 5. Summary of intervention impacts.

\begin{tabular}{|c|c|c|c|c|c|}
\hline \multirow{2}{*}{ Type of Intervention } & \multicolumn{4}{|c|}{ Reported Impact } & \multirow{2}{*}{ Total } \\
\hline & Positive & Mixed & Negative & No Effect & \\
\hline \multicolumn{6}{|c|}{ Norms and standards (formal and informal) } \\
\hline Accreditation & & & & 1 & 1 \\
\hline Guidelines & 2 & & & & 2 \\
\hline Public reporting & & 4 & & & 4 \\
\hline Restrict over-the-counter sales & & 2 & & & 2 \\
\hline Prescription control & & & & & 0 \\
\hline \multicolumn{6}{|c|}{ Knowledge } \\
\hline Audit/Feedback & 4 & & & & 4 \\
\hline Education & 2 & & & 1 & 4 \\
\hline Education/Feedback & 4 & 1 & & & 4 \\
\hline Education/Feedback/Regulation & 1 & & & & 1 \\
\hline Information & & & & & 0 \\
\hline \multicolumn{6}{|c|}{ Decision support } \\
\hline Algorithms & 1 & 1 & & & 2 \\
\hline Diagnostics & 1 & & 1 & & 2 \\
\hline \multicolumn{6}{|c|}{ Supply chain } \\
\hline Decentralisation of Supply & & & & & 0 \\
\hline Drug Delivery & & & & & 0 \\
\hline \multicolumn{6}{|c|}{ Economic } \\
\hline Financial incentives & 1 & & & & 1 \\
\hline Pricing strategy & & & 1 & & 1 \\
\hline Health Insurance & & & 1 & & 1 \\
\hline \multicolumn{6}{|c|}{ Organisational/management systems } \\
\hline Essential Medicine Policy & & 4 & 1 & 1 & 6 \\
\hline Stewardship Programme & 5 & 1 & & & 6 \\
\hline Total & 21 & 13 & 4 & 3 & 41 \\
\hline
\end{tabular}

Number of studies: $1-2$

Given that past reviews have found evidence suggesting that multifaceted interventions have greater impact than single interventions, we checked if similar trends were observable in our studies. We classified 21 studies as using multiple/mixed intervention strategies (e.g., education with feedback or monitoring, or stewardship programmes which are multi-strategy) and 19 as using single change pathways (e.g., one intervention modality, such as training). In one study, the approach was unclear. This study was a survey of doctor's prescribing practice which included questions on whether they had received training on antibiotic use, however no details of the training were given. Table 6 shows that although both single and multifaceted interventions produced positive and mixed results, the majority of studies reporting mixed or positive results were multifaceted studies (positive and mixed combined $=20$ versus 13) and studies evaluating single pathway interventions reported no or negative effects more frequently (negative and no effect combined $=1$ versus 6 ). Indeed, none of the interventions 
classified as having mixed pathways reported negative results, and only one concluded there was no effect (see Appendix C for more detail).

Table 6. Results, by intervention approach.

\begin{tabular}{cccc}
\hline \multirow{2}{*}{ Reported Results } & \multicolumn{2}{c}{ Intervention Pathway } & \multirow{2}{*}{ Total } \\
\cline { 2 - 3 } & Single & Mixed/Multifaceted & \\
\hline Positive & 8 & 12 & 20 \\
Mixed & 5 & 8 & 13 \\
Negative & 4 & 0 & 4 \\
No effect & 2 & 1 & 3 \\
Total & 19 & 21 & 40 \\
\hline
\end{tabular}

\subsection{Prescribing and Intervention Contexts}

The review identified 32 context studies, from 18 different countries. One study was multi-country [13] while the rest described specific country contexts, which are listed in Appendix D. These studies described the context of interventions aiming to address antibiotic supply in hospitals, primary care and pharmacy settings, including public, private and informal providers. At least five studies looked specifically at drug shops, community pharmacists and informal village doctors. Only one study describing use of antibiotics in animal health was identified.

\subsubsection{Knowledge of Antimicrobial Resistance and Appropriate Antibiotic Use}

A number of studies identified limited knowledge of antimicrobial resistance (AMR) and of appropriate drug use in a range of levels and sectors, for example surgeons in Jordon [14], tertiary and primary care doctors in China [15], doctors in Laos [16], public and private doctors and pharmacists in India [17] and drug sellers and pharmacists in Vietnam [18]. Bai et al. [15] found that, although age and gender did not appear to be associated with knowledge scores in Chinese settings, it was related to level of training, with more senior doctors performing well, and primary care doctors having lower levels of knowledge than tertiary care doctors. In India, urban doctors seemed to have better knowledge of AMR than rural ones [17]. Similarly, accreditation was not associated with improved knowledge and prescribing among drug sellers and pharmacists in Vietnam; however, level of training was, which in turn mapped onto urban-rural differences, with rural pharmacists being less qualified than urban ones [18]. In contrast, Reynolds and Mckee's [19] in depth study of knowledge and practice among Chinese health workers found that awareness of resistance was high (although understanding of mechanisms was limited), but despite this health workers still prescribed inappropriately due to incentives listed in the next Section.

\subsubsection{Practical Concerns and Diverse Influences on Antibiotic Prescribing}

Research pointed to structural issues impeding healthcare workers' ability to adhere to standards and guidelines. For example, in Jordan, surgeons reported that appropriate drugs were absent [14], as did pharmacists in India [20].

Beyond medicine availability, there appear to be myriad more subtle influencing factors. Studies of doctors $[17,19,20]$ identified the following factors as influencing prescribing: (i) inadequate diagnostic facilities; (ii) lack of antibiotic guidelines; (iii) difficulty in observing patient progress (e.g., patients do not return for test results and follow up, especially in poorer areas and in public clinics where they cannot afford tests); (iv) poor intensive care facilities in rural areas; (v) patient demand for quick relief; (vi) perceived patient expectation from past prescriptions; (vii) using up stock; and (viii) fear of losing patients to competition (for private practices). Kotwani et al. [20] noted that doctors in the public sector complained they did not have enough time during each consultation to cover patient history in depth or to dissuade patients from wanting antibiotics. 
Pharmacists and drug sellers $[17,20,21]$ had a similar list of influences: (i) patient demand; (ii) a belief that cure is through antibiotics; (iii) competition from other pharmacy shops; (iv) antibiotic sales promoting business; (v) the need to use up stock; and (vi) distance and costs of reaching care facilities. Notably, public sector pharmacists in India reported overprescribing antibiotics to deal with stock which was nearing its expiry date [20]. They did not return stock as it was a lengthy process and more senior officials pressured them to use up stock. Drug shop owners in Tanzania attributed their unnecessary sales of antibiotics to: customer demand, habit ("mazoea"), following inappropriate health facility prescriptions, the need to make a profit (e.g., sell more expensive medicines), and also the need to use up stock [22]. Significantly, for these private sector providers, they were disinclined to refer patients to doctors, as it could result in their patients/customer base losing confidence in them; thus, not selling drugs had short- and potentially long-term negative effects on profit.

An enlightening study from Vietnam [18] found that antibiotics were not the most profitable drug for sellers, although it was the most commonly sold drug and the mark up did vary considerably; antibiotics contributed $24 \%$ and $18 \%$ of total revenue in urban and rural pharmacies, respectively, while herbal remedies contributed $24 \%$ and $27 \%$.

\subsubsection{Industry Influence}

The influence of the pharmaceutical industry in providing information and incentives looms large $[17,23-25]$. In Nigeria, both public and private hospitals' doctors indicated that industry was their primary source of information about drugs [23]. Indian doctors and pharmacists reported coming under pressure and being offered incentives by pharmaceutical companies to use or sell drugs, especially newer brands [17]. A study of doctors in Pakistan found that private sector doctors were (reportedly) more susceptible to patient demand and to fear of losing patients to other providers than their public sector counterparts, while public sector doctors were more likely to face problems with the availability of drugs [26]. In Laos, doctors in provincial settings were more likely to receive information from drug companies than doctors in district and central hospitals [16].

In their study of healthcare worker incentives in China, Reynolds and Mckee [19] found that some doctors had arrangements with pharmaceutical companies to split the profits of extra sales. This was in addition to the sanctioned cost recovery incentives (pre-2009 Chinese policy reforms).

\subsubsection{Care and Responsibility}

Studies identified additional cultures of care that influenced prescribing, suggesting the idea that prescribers and sellers are primarily influenced by stock and profits may be an over simplification. Indian pharmacists said the antibiotics they sold to poor patients was akin to social work [20]; and Indian doctors said they prescribed antibiotics as prevention as their patients living with poor sanitation and in unhygienic conditions were susceptible to infection [27]. There was also some reluctance for pharmacists to challenge doctor's authority by contesting prescriptions even if they knew they were unnecessary [20].

\subsubsection{Perceptions of Public Perception}

Many of the studies include health worker's perceptions of the public and their demands. A common perception among doctors is that patients do not know about diseases and desire antibiotics as a result [17]. In Nigeria [23], doctors say that when the public pay for health services, i.e., in private hospitals, they expect medicines to be in their bills. Providers in both the public and private sector stated that patient demand was a key factor in their prescribing $[15,17,19,20,22,26-28]$. However, it is not clear what evidence these views are based on and whether they involve misperceptions on the part of providers. In Sri Lanka, Tillekeratne et al. [28] found that although patients admitted expecting drugs they were not specifically demanding antibiotics. 


\subsubsection{Perspectives on Interventions}

Some studies asked participants for suggestions of interventions to improve antibiotic use, which included: creating public awareness, better healthcare provider communication, improved diagnostic support, stricter implementation of guidelines, continuing education, and strengthening of regulations [17]. There was an appetite for training [16,29]. For example, in Laos, a large majority of doctors surveyed were in favour of educational programmes, whereas only $45 \%$ of doctors thought guidelines were effective [16]; indeed, some doctors thought that guidelines were more of an obstacle than a help (22\%). South African medical students expressed a preference for e-learning platforms, but significantly did not appreciate more interactive learning techniques such as "problem-based learning" or "registrar interaction" (i.e., interaction with senior colleagues, in this case trainee specialists) [30]. This could reflect poor implementation of these learning modalities but it suggests that clarification is needed of their role in education.

\subsubsection{Policy Coordination}

In Bangladesh, the progressive and once highly acclaimed National Drug Policy of 1982 has not been maintained [31]; the regulatory institutions do not have power to curb prices or excess use-generics less available, high mark up and sale of antibiotics for cough and fever. Bangladesh's experience serves as an important reminder, for example in relation to China's apparently effective essential drug reform, that there must be sustained investment into the comprehensive implementation of policy especially those which address antibiotic use as part of other agenda's such as universal health coverage. A policy analysis in Namibia [32] highlighted inconsistency in national policy frameworks. While treatment guidelines (e.g., HIV, malaria, tuberculosis, etc.) included recommendations about antibiotics there was no overarching guideline for antibiotics; meanwhile, many of the antibiotics included on the essential medicine list were not included in the treatment guidelines, and vice versa. The study noted that lack of coordination between the committees developing these lists had led to confusion with implications for clinical practice. Similarly, in China, doctors complained about the number of new guidelines and no single authoritative source [19]. It is relevant that the only international study, a survey of hospital-based stewardship initiatives [13], found that major barriers included funding and human resources, suggesting sustainable implementation is a challenge.

\subsubsection{Unintended Consequences}

The management of fevers and common illnesses in outpatient settings is a significant problem. A study examining the appropriateness of treatment in Papua New Guinea [33] found there was poor compliance with the Integrated Management for Childhood Illness guidelines (ICMI) and that $40 \%$ of children were not treated accurately: $29 \%$ received antibiotics when they should not have and $11 \%$ did not receive antibiotics when they should have done. They observed that the prescription of antibiotics was strongly influenced by the result of rapid diagnostic tests (RDTs) for malaria in feverish patients: in children presenting with criteria for mild pneumonia (who should receive antibiotics), only $40 \%$ were treated when the malaria RDT was positive, compared to $76 \%$ when the test was negative. This suggests that health workers are primarily following RDT results and ignoring other clinical symptoms, meaning the management of co-morbid bacterial and malarial infections are poorly managed. Several studies point to the inadequacies of apparently simple methods (e.g., fever charts or RDTs) of managing fevers and antibiotic use successfully at the community level [34,35]. Comprehensive follow up of patients who may have co-morbid infections or who may have been misdiagnosed should be a priority.

\subsubsection{Animal Health}

Finally, only one context study covered use of antibiotics in agriculture. Aquaculture farmers in Vietnam were asked about AMR [36]. Approximately half of farmers surveyed used antibiotics, primarily as prophylaxis, which they bought directly from manufacturers not through veterinarians. 
Farmers were not aware of regulations about antibiotic use and their main sources of information was from drug manufactures, including in seminars jointly arranged by the companies and local government.

\section{Discussion}

The review confirms previous studies [4-6] that have found that multiplex interventions combining different strategies to influence behaviour tend to have a higher success rate than interventions based on single strategies. Another similarity to other reviews [4] is that many of the interventions which worked well combined restrictive and enabling strategies, i.e., educational techniques combined with forms of monitoring. To the best of the authors' knowledge, this is the largest review to document these patterns in LMIC countries.

The inclusion of evidence on prescribing contexts provides important additional insight. These studies highlighted a web of interacting influences on prescriber behaviour that cannot be reduced to simple motivations, such as profit. Instead, health system quality and availability, education, perceptions of patient demand, bureaucratic processes, competition, and cultures of care all play a role.

Physician perceptions of patient demand $[15,17,19,20,22,26-28]$ requires more attention as observations do not always support this [28]. Indeed, elsewhere studies that have observed clinical interactions have shown how doctors prescribe irrespective of patient demand [37] and that patient satisfaction is not necessarily linked to whether a prescription was received [38], although these studies are old. A more recent study from multiple European settings [39] found that, while patients frequently hope for and expect antibiotics, it is less common for them to ask for them explicitly. Patients were prescribed antibiotics considerably more often than they asked for them (54\% compared to $10 \%$, respectively), and more than was clinically necessary. The same study found that, in general, patients were satisfied with their consultations, whether prescribed antibiotics or not. Assessing the level and influence of patient demand is difficult as research is often based on reported behaviour and perceptions rather than observations.

It is striking the extent to which different providers blame others within the system: health workers blame patients, pharmacists blame doctors and their incorrect prescriptions, and drug sellers blame competitors saying patients will just "go somewhere else". Such blame shifting highlights a more general importance of interactions between people within the health system: pharmacists fear challenging doctors' prescriptions, drug sellers fear losing their customers, and many doctors and pharmacists get a large proportion of their information about antibiotics from drug detailers who also offer incentives. In discussions of interventions to address AMR, the temptation is to focus on awareness raising and changing the behaviour of individuals, be they healthcare workers including prescribers and pharmacists, or patients. However, the stewardship, supply and use of antibiotics in human and animal healthcare is best viewed with a broad systemic lens $[2,40]$. This encompasses an appreciation of how the behaviour of individuals is mediated by a range of structural and contextual factors operating at different scales, which can affect individual agency and decision-making.

Scholars have advocated for a consideration of behavioural change interventions within the context of everyday social practices [41]; for a whole system approach (at macro, meso and micro levels) to analysing policy outcomes in the health sector [42]; for a consideration of formal and informal health markets for drugs and services for both people and animals [7,43]; for an appreciation of incentive structures in drug supply chains and the effects on over-the-counter drug retailers and informal providers [44]; and for an approach to healthcare worker behavioural change interventions that appreciates individual rationales as well as the contextual settings in which specific behaviours are practiced [45]. The overall view is also one of decentred governance and regulation, which departs significantly from traditional "command and control" models [46]. It is notable therefore that while a majority of studies we identified in this review implemented multiplex interventions, most of these took place within one health setting, e.g., a stewardship programme in a hospital. Very few studies targeted different kinds of healthcare provider and different kinds of health settings. One exception 
was by Hoa et al [47] who attempted an educational programme for all providers in one district, public, private, formal and informal and primary or secondary care. In this example, however, there was a particularly high drop-out rate among informal providers illustrating the challenges of engaging hard to reach groups in interventions. Moreover, important interactions between types of providers are not being addressed and it is rare to find examples of whole system approaches which have been recommended [2,40]. China provides one of the few examples of system-wide interventions at the national and regional level. There is a need for coordinated action and research across multiple settings and actors throughout and between the human and animal supply chain.

Significantly, our study was unable to identify a single study on interventions that addressed prescribing behaviour for veterinary use of antibiotics, and only one context study on agricultural use. Evidence is emerging that antibiotics critical for human health are being used in animal farming [48] including colistin $[49,50]$. Research needs to address agricultural use of antibiotics and its overlap with human health system in terms of the antibiotics used, healthcare personnel, and transmission pathways of resistant pathogens. Measures to improve essential medicine use provides a precedent for success [51]. The National Action Plan process provides an opportunity to facilitate this. In particular, employing the "One Health" lens [52,53], taking the intersection among human, veterinary, and environmental health into account, can help address the multi-sector nature of AMR and develop systematic strategies to tackle this challenge.

In addition to the major lack of evidence documenting the effectiveness of interventions to improve veterinary prescribing, this review has identified some gaps in the human evidence. Studies in hospitals were most common, possibly as hospitals are more observable and controllable environments. The overwhelming majority of studies evaluated interventions at public facilities. There was also a majority of studies from urban areas, with less from rural areas, possibly because hospitals are over represented in the data and tend to be in urban areas. Private providers, and in particular those in primary care settings, is another gap. Informal private providers are especially underrepresented. Evidence from LMICs suggests that rural and/or poor people extensively rely on healthcare services provided by informal practitioners and suppliers of drugs [54,55]. Therefore, understanding the antibiotic prescribing practices of the informal providers, and improving them, has important implications for health of many marginalized people. There were no interventions in this review involving drug retailers or the pharmaceutical companies despite their prominent role in the contextual studies.

Public understanding and demand is a critical piece of the puzzle and requires action but it must be based on accurate understandings of lay knowledge and demand otherwise messaging and educational interventions will fail. Research is needed into public views and their influence on demand and prescriber behaviour. This should form part of a holistic view of supply and demand.

Our study has a number of limitations. While the literature search was extensive, it may not be exhaustive and studies prior to 2000 were not included. The large number of heterogeneous studies meant we were unable to assess quality of the evidence in detail and we did not compare or combine the effects of selected studies. Further research is needed to assess the strength and magnitude of effects for promising interventions. A majority of studies $(n=20)$ reported positive effects while far fewer reported mixed, negative or no effects $(n=13,4$ and 3 respectively). This indicates that publication bias may be an issue. Nevertheless, the review was able to identify trends and gaps in the evidence base.

\section{Conclusions}

The evidence collected in this review comes from a range of health care settings, for example hospitals, primary care, pharmacists or drug shops, and from interventions targeting different types of health providers including doctors, nurses, and drug sellers. This review has identified evidence on interventions to improve antibiotic use among providers in LMIC settings, which, in the authors' opinion, has not been well represented in previous reviews. The review found that multiplex interventions that combine different strategies to influence behaviour tend to have a higher 
success rate than interventions based on single strategies. However, the evidence base is uneven with hospital and urban contexts over-represented for interventions. There is much less evidence on private providers, especially in primary care settings. Informal private providers who play a major role in drug distribution in LMICs are especially underrepresented. Furthermore, there were no interventions involving drug detailers or the pharmaceutical companies despite their prominent role in the contextual studies. Strikingly, no study was identified that addressed veterinary prescribing of antibiotics.

Evidence on prescribing contexts highlights a web of interacting influences on prescriber behaviour including health system quality and availability, education, perceptions of patient demand, bureaucratic processes, profit, competition, and cultures of care. These contextual studies underscore the importance of interactions between different people within the health system. Although a majority of studies implemented multiplex interventions, most of these took place within one health setting, e.g., a stewardship programme in a hospital. Very few studies targeted different kinds of health provider and interactions across different kinds of health setting. There is an urgent need for coordinated multi-actor studies including multiple settings, by taking a One Health approach, including agricultural settings, and actors throughout the supply chain.

Author Contributions: Conceptualization, A.W., A.E. and H.M.; Methodology, A.W. and A.E.; Analysis, A.W., A.E. and H.M.; Writing-Original Draft Preparation, A.W.; and Writing-Review and Editing, A.E. and H.M.

Funding: This research was commissioned by the Wellcome Trust.

Acknowledgments: the authors would like to thank Aditi Bhonagiri and Tanvir Ahmed for their research assistance conducting searches and reviewing manuscripts.

Conflicts of Interest: The authors declare no conflict of interest.

\section{Appendix A}

Table A1. Search parameters.

\begin{tabular}{ll}
\hline Parameter & \multicolumn{1}{c}{ Definition } \\
\hline Population & $\begin{array}{l}\text { People who supply antibiotics to sick people or animals, e.g., doctors and other healthcare } \\
\text { prescribers, drug sellers, informal doctors, pharmacists, community health workers, } \\
\text { veterinarians, farmers, community animal health workers }\end{array}$ \\
\hline Problem & Unnecessary or inappropriate use of antibiotics \\
\hline Intervention & $\begin{array}{l}\text { Any intervention aiming to influence the prescribing or sale of antibiotics (formal and } \\
\text { informal), e.g., communication and education, stewardship programmes, treatment } \\
\text { algorithms, delayed treatment, alternative treatments, incentives, pricing, packaging, } \\
\text { legislation, peer or community oversight. }\end{array}$ \\
\hline Comparison & $\begin{array}{l}\text { Not applicable. The review is not limited to controlled or comparative research designs. } \\
\text { Studies which report on interventions with or without comparison groups are included }\end{array}$ \\
\hline Context & $\begin{array}{l}\text { Hospital, outpatients, community, online, formal and informal systems in LMICs only. } \\
\text { Outcome }\end{array}$ \\
$\begin{array}{l}\text { Primary: Measured improvement in antibiotic use (e.g., reduction in unnecessary antibiotic } \\
\text { prescribing, improved adherence to guidelines) } \\
\text { Other outcomes could include: Reported changes in knowledge and attitudes around } \\
\text { antibiotic use, e.g. health outcomes (improved, unaffected, or adverse), levels of antibiotic } \\
\text { resistance and unintended consequences }\end{array}$ \\
\hline
\end{tabular}

\section{Appendix B}

\section{Search Terms}

Bibliographic database searches combined the following sets of terms:

(1) Activity/Outcome of interest:

antibiotic AND (prescribing OR sale OR prescribing OR prescription OR selling OR availability OR consumption or dosage OR use) 
(2) Type of intervention:

- "Behaviour change"

- $\quad$ stewardship

- drug policy

- drug financing

- drug committee

- $\quad$ Marketing / social marketing

- Communication

- Outreach

- "community engagement"

- Evaluation

- Training

- Guideline\$

- Algorithm

- curriculum

- " "mass media"

- Information

- $\quad$ Television

- Radio

- Newspapers

- Booklets

- Pamphlet

- Posters

- Leaflets

- Advocacy

- Advice

- $\quad$ Fines

- Incentive\$

- "financial incentive\$"

- "financial intervention\$"

- $\quad$ Fees

- formularies

- Tax

- Taxation

- Prohibit

- Prohibition

- Ban

- Regulation

- Legislation

- Reform

- Restrict

- Restriction

- Reminder\$

- "Peer supervision"

- Subsidy

- Subsidi\$ation 


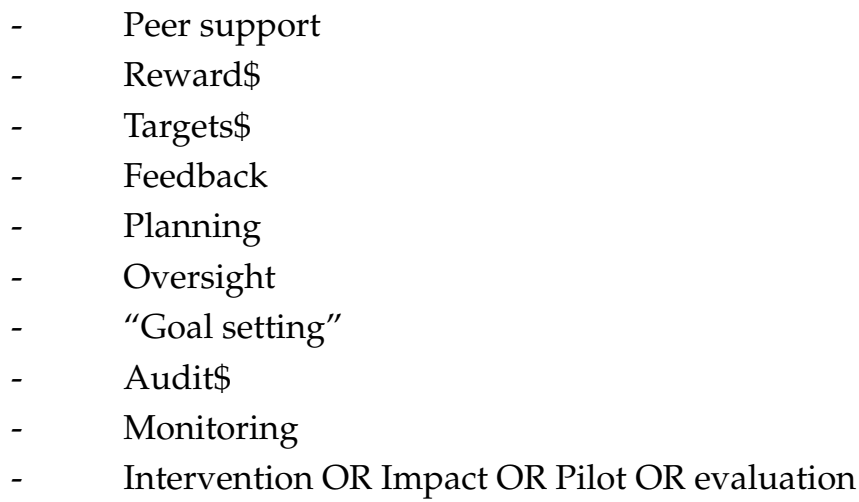

\section{Appendix C}

Descriptions of interventions $(n=41)$ and factors associated with their effectiveness.

\section{Norms and Standards}

Guidelines were found to be effective in hospital settings, either when they were locally developed or formed part of a comprehensive national reform programme. In the study by Zhang et al. [56], five Chinese hospitals reduced their antibiotic consumption after the introduction of national guidelines. However, very little information is provided about their implementation in hospitals and what strategies may have supported it. Although the specificity of Chinese policy making contexts (e.g., a backdrop of major health and economic reforms, and a relatively strong government) must be taken into account when considering generalisability, the study does provide observational evidence (measured two years after their introduction) that guidelines can be part of effective response to the overuse of antibiotics. Ristic et al. [57] recorded a positive effect of new guideline for prophylactic use of antibiotics in Caesarean deliveries in a Serbian hospital. These guidelines were locally developed and educational sessions accompanied their implementation suggesting a degree of ownership.

Public reporting interventions produced mixed results. Public opinion/expectations and peer comparison appear to influence prescribing behaviours but in contrasting ways depending on the disease, patient cohort and doctor's ranking. Liu et al. [58], Tang et al. [59], Tang et al. [60], and Yang et al. [61] reported effects of public reporting in primary care settings in China. Data on antibiotic prescribing (percentage of prescriptions including antibiotics or injections, and cost) were collected and individual doctors and facilities were compared and rankings were published publicly, e.g., on posters outside facilities. The studies note differences in the effect of public reporting between diseases and age groups according to public perception about appropriateness of prescribing for these categories of illness or people. The intervention also influenced doctors differently according to their ranking, and, in the study by Tang et al. [60], doctors categorised as "low prescribers" did not change their habits, even though they could have reduced usage further. These findings indicate that social norms around prescribing are interdependent and must be considered otherwise they can undermine even apparently simple interventions.

Restricted over-the-counter sales: Santa-Ana-Tellez et al. [62] and Moura et al. [63] evaluated the effect of controlling over-the-counter sales of antibiotics at pharmacies. National policies imposed financial penalties and closure of businesses if antibiotics are prescribed without prescription. These studies find mixed results but the implementation and reasons for the mixed results (e.g., reductions in Mexico but not Brazil, or in urban or private settings rather than rural or public sector) are not examined in detail.

Accreditation on its own is an insufficient motivator and regulator of antibiotic sales in private sector drug shops. Minzi et al. [64] compared dispensing practices at certified drug sales outlets to non-certified outlets. To gain accreditation, drug shops took part in a training to meet specified quality criteria. After accreditation, the shop would then be allowed to sell a limited range of prescription-only essential medicines and to receive additional support through regular supervision, refresher training, 
and commercial incentives such as training in business skills and access to microfinance. However, adherence to prescribing guidelines was no better in accredited shops than non-accredited shops; indeed, accredited shops were more likely to prescribe antibiotics without prescription and less likely to refer patients appropriately. The authors noted that many of the staff who had received training and gone through the accreditation process were no longer working in the shops, limiting the retention of institutional knowledge from training interventions.

\section{Knowledge Based Strategies}

A number of interventions began with training sessions but supplemented them with additional components.

Audit and feedback: Successful interventions involved repeated feedback combined with supportive face-to-face educational strategies and monitoring, and similar approaches demonstrated effectiveness in both hospitals and primary care settings. Awad et al. [65], Eltayeb et al. [66], Messina, van den Bergh and Goff [67], and Shen et al. [68] evaluated the effects of auditing prescribing behaviour and providing feedback in hospitals and primary care settings. Interventions spanned between six months and one year. All interventions aimed at appropriate antibiotic prescribing and included combinations of: audit and feedback, expert review, regular reporting to management/superiors, reminders, recommendations and discussion of inappropriate prescribing, educational seminars and face-to-face training sessions. Awad et al. [65] and Eltayeb et al. [66] tested different combinations of intervention and found that audit and feedback alone was less effective than when combined with other educational and monitoring components.

Education and feedback: To different degrees, Apisarnthanarak et al. [69], Bantar et al. [70], Kafle et al. [71] and Opondo et al. [72] combined education, support and monitoring into multi-faceted interventions. Components included: Theoretical and practical training sessions, tools (e.g., clinical guidelines and job-aids), management processes (e.g., order/request forms), regular supervision from senior colleagues, opportunities to discuss implementation of guidelines, facilitators/champions, and face-to-face and peer-group discussion and feedback on performance. Three were hospital based and one was in a primary care setting. These interventions had education at their core but combined knowledge with restrictive and enabling approaches.

Education/feedback/regulation: Chuc et al. [73] took a regulatory focused approach to their intervention in pharmacies in Vietnam, but combined it with education and peer-support mechanisms. The intervention involved: visits from inspectors to assess compliance with prescription drug regulation, educational sessions, and the identification of peer leaders to devise peer influence strategies. As above, successful interventions combined restrictive and enabling approaches, and importantly demonstrated effectiveness in private sector pharmacies. Notably, there was considerable emphasis on formal regulatory institutions, including inspections, which would require adequate resources to be effective over sustained periods of time.

Education: Training can be effective, but there is a gap between actual practice and reported practice, with doctors underestimating or underreporting antibiotic prescribing. Two studies examined straightforward training interventions. Shrestha et al. [74] evaluated a five-day training course on new WHO lung health prescribing guidelines for primary care settings. Sun et al. [75] assessed knowledge, attitude and practice of doctors in China. Doctors who had attended training reported that they were less likely to prescribe antibiotics. However, a separate analysis of prescriptions revealed high levels of antibiotic prescribing. Esmaily et al. [76] assessed a two-day training course for primary care doctors on the principles of prescribing and found no improvement, although the intervention was not extensive.

\section{Decision Support}

Algorithms: There is high quality evidence showing that algorithms can improve patient management and reduce antibiotic prescribing in paper or electronic form. However, more specific 
diagnostic and case management approaches must be balanced with comprehensive follow up of patients, otherwise cases could be missed. Shao et al. [77] evaluated a new algorithm to assist with the integrated management of childhood illnesses. The quasi-experimental study documents a large and statistically significant improvement in adherence to guidelines between the control (usual practice) and intervention group. The study is conducted in primary care settings. Rambaud-Althaus et al. [78] evaluated the effect of case management algorithms that assist with diagnosis and integrated management of common illness among children in primary care settings. They compared a control group to two different methods of algorithm support: paper-based and electronic (smart phone). While both paper and smartphone-based algorithms are shown to decrease antibiotic use, they do so without being able to identify which patients do need antibiotics and so compared to the control there were large numbers of patients who needed antibiotics but who did not receive them. In effect, the control arm is highly sensitive but not specific, whereas the intervention arms are more specific but less sensitive. Patient follow up must be improved and is relevant to addressing resistance and tackling common health problems.

Diagnostics: Misdiagnosis of bacterial diseases as flu, and misguided use of antibiotics for flu, can be reduced using a rapid influenza test in outpatient settings. Bhavnani et al. [79] evaluated a rapid diagnostic test for influenza in outpatients in rural Thailand and found that a negative influenza result was associated with reduced antibiotic use. However, the scale of the reduction was modest, suggesting that comprehensive reductions will require more than improved diagnostics.

\section{Economic Strategies}

Financial incentives: There is evidence that comprehensive changes to financial incentive structures can have positive impacts and be achieved within public primary care settings. Yip et al. [80] evaluated the effects of changing from a fee-for-service to a performance-based system in 28 primary care settings in China. Operating within China's public health insurance system, 30\% of each facilities' budget was withheld, and they were subject to a performance review. Based on the results of the review, the money that had been withheld was shared among the top performing facilities. The study documents decreased antibiotic use, mostly due to reduced injectable antibiotics. Centralised management was important to the effectiveness of financial incentives in this case.

\section{Organisational/Management Strategies}

Stewardship programme: Comprehensive stewardship campaigns using multiple approaches resulted in substantial reductions in antibiotic use and sales in both hospitals and pharmacies. Kallel et al. [81], Ma et al. [82], Ozkurt et al. [83], and Zhang et al. [84] evaluated effects of stewardship programme at secondary or tertiary hospitals while Marković-Peković et al. [85] studied effects at pharmacies. The interventions involved: The formation of expert interdisciplinary groups to provide oversight and guidance, knowledge dissemination, clinical training, academic engagement (e.g., participation in conferences and seminars), monitoring, feedback, data management and verification, the development of new guidelines and targets and financial penalties. In the study by Ma et al. [82], doctors not meeting the new standards had their salary deducted, and, in the study by Marković-Peković et al. [85], pharmacists were fined for selling antibiotics over the counter. This latter study with pharmacists also includes public awareness campaigns and policy coordination, as part of a larger national stewardship effort. However, the authors also found that pharmacists gave less oral or written advice alongside antibiotic sales, which they suggested could indicate an attempt to obscure banned practices. Increased restriction on sales could prompt sellers to sell drugs in more underhanded or unsafe ways. Magedanz et al. [86] addressed a stewardship programme and in particular an audit-and-feedback component focusing on restricting certain classes of antibiotic. This resulted in uneven patterns of use, with success is reducing use of some antibiotics seemingly driving increased use of others. While restricting classes of antibiotics can be effective especially in the short term, it 
may drive increased use for other drugs which may not be sustainable over the longer term when reductions in usage across the board are required.

Essential medicine policies had mixed effects and highlight the need to integrate action on antibiotic use with other health system initiatives. Ding et al. [87] and Wei et al. [88] addressed the effects of China's essential medicines policy on levels of antibiotic use in hospitals while Song et al. [89] and Yao et al. [90] studied its effects in primary care settings. Essential medicine policies are multifaceted involving: establishing a list of essential drugs, supply chain measures and price control. Results were mixed across regions, urban-rural settings and different facilities, depending on implementation. Use of some antibiotics increased or decreased depending on their inclusion on the lists, as did cost of treatment. Some interventions coincided with other initiatives (e.g., hospital-level stewardship programme) which made it hard to separate effects, including from wider health system reform (e.g., "no mark-up" policy) and delivery (e.g., health insurance programmes) and could be responsible for changes in use. Yang et al. [91] evaluated China's national essential medicine policy and found that, although availability and cost of essential drugs increased, there was no reduction in the number of antibiotics prescribed. This is likely due to the fact that the policy focuses on extending access to quality and reasonably priced drugs and not explicitly on prudent use of drugs (see below). Essential medicine lists provide a policy framework for implementing change at scale but prudent use of antibiotics needs to be considered in their design, otherwise they will not lead to significant reductions in use.

\section{Studies with Negative Results}

Four studies documented increased rates of antibiotic prescribing or increased levels of inappropriate antibiotic use. The interventions associated with these negative findings were Nigeria's essential drug policy [92], China's national health insurance policy [93], changes in fee structure in Nepal [94] and rapid malaria diagnostics [95]. All interventions were conducted at the national level and, with the exception of the malaria RDT, their focus was on improving access to medicines rather than aiming to reduce antibiotic use or to improve antibiotic prescribing practices (hence their authors would not view them as unsuccessful or as having "negative" results). We have described these separately to emphasise the need to align policies and consider unintended consequences. In the case of the Malaria RDTs [95], improvements in diagnosing malaria were not matched by improvements in the diagnosis of bacterial disease. An unintended consequence of malaria RDTs is that the reductions in unnecessary use of antimalarial drugs have been offset by increases in antibiotics prescription in cases where the RDT is negative for malaria. Unless action on extending access is coordinated with action to improve use there is potential for interventions to be in conflict.

\section{Appendix D}

List of context studies and countries

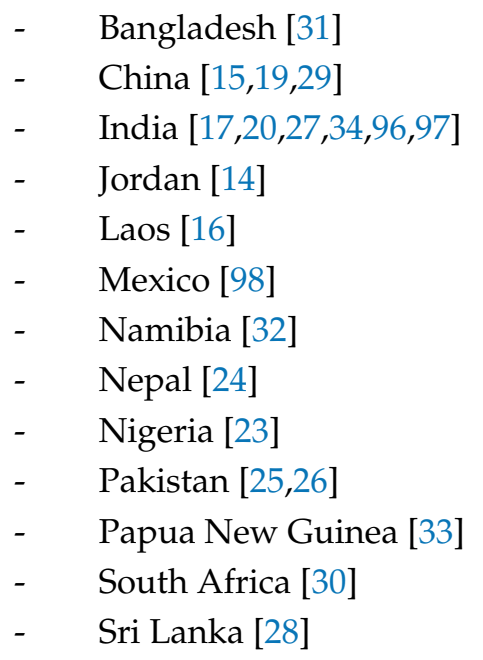


- $\quad$ Sudan [21]

- $\quad$ Tanzania $[22,35,99,100]$

- $\quad$ Thailand [101]

- $\quad$ Turkey $[102,103]$

- $\quad$ Vietnam $[18,36]$

\section{References}

1. Klein, E.Y.; van Boeckel, T.P.; Martinez, E.M.; Pant, S.; Gandra, S.; Levin, S.A.; Goossens, H.; Laxminarayan, R. Global increase and geographic convergence in antibiotic consumption between 2000 and 2015. Proc. Natl. Acad. Sci. USA 2018, 115, E3463-E3470. [CrossRef] [PubMed]

2. Buckland-Merrett, G.; Bloom, G.; Wilkinson, A.; MacGregor, H.M. Towards the just and sustainable use of antibiotics. J. Pharm. Policy Pract. 2016, 9, 31. [CrossRef] [PubMed]

3. Malhotra-Kumar, S.; Lammens, C.; Coenen, S.; Van Herck, K.; Goossens, H. Effect of azithromycin and clarithromycin therapy on pharyngeal carriage of macrolide resistant streptococci in healthy volunteers: A randomised, double-blind, placebo controlled study. Lancet 2007, 369, 482-490. [CrossRef]

4. Davey, P.; Marwick, C.A.; Scott, C.L.; Charani, E.; Mcneil, K.; Brown, E.; Gould, I.M.; Ramsay, C.R.; Michie, S. Interventions to improve antibiotic prescribing practices for hospital inpatients. Cochrane Database Syst. Rev. 2017, 2, CD003543. [CrossRef] [PubMed]

5. Arnold, S.R.; Straus, S.E. Interventions to improve antibiotic prescribing practices in ambulatory care. Cochrane Database Syst. Rev. 2005, 4. [CrossRef] [PubMed]

6. Ivanovska, V.; Holloway, K.A. Interventions to improve antibiotic prescribing in upper middle income countries: A systematic review of the literature 1990-2009. Maced. J. Med. Sci. 2013, 6, 84-91.

7. Bloom, G.; Wilkinson, A.; Tomson, G.; Awor, P.; Zhang, X.; Masud Ahmed, S.; Wasif Ali Khan, B. Addressing Resistance to Antibiotics in Pluralistic Health Systems; STEPS Working Paper; STEPS Centre: Brighton, UK, 2015.

8. Chandler, C.; Webb, E.; Maiteki-Sebuguzi, C.L.; Nayiga, S.; Nabirye, C.; Liberto, D.; Ssemmondo, E.; Dorsey, G.; Kamya, M.; Staedke, S. The impact of an intervention to introduce malaria rapid diagnostic tests on fever case management in a high transmission setting in Uganda: A mixed-methods cluster-randomized trial (PRIME). PLoS ONE 2017, 12, e0170998. [CrossRef] [PubMed]

9. Hutchinson, E.; Hutchison, C.; Lal, S.; Hansen, K.; Kayendeke, M.; Nabirye, C.; Magnussen, P.; Clarke, S.E.; Mbonye, A.; Chandler, C.I.R. Introducing rapid tests for malaria into the retail sector: What are the unintended consequences? BMJ Glob. Health 2017, 2, e000067. [CrossRef]

10. Colquhoun, H.L.; Levac, D.; O’Brien, K.K.; Straus, S.; Tricco, A.C.; Perrier, L.; Kastner, M.; Moher, D. Scoping reviews: Time for clarity in definition, methods, and reporting. J. Clin. Epidemiol. 2014, 67, 1291-1294. [CrossRef]

11. Miake-Lye, I.M.; Hempel, S.; Shanman, R.; Shekelle, P.G. What is an evidence map? A systematic review of published evidence maps and their definitions, methods, and products. Syst. Rev. 2016, 5, 28. [CrossRef]

12. Arksey, H.; O'Malley, L. Scoping studies: Towards a methodological framework. Int. J. Soc. Res. Methodol. 2005, 8, 19-32. [CrossRef]

13. Howard, P.; Pulcini, C.; Levy, H.G.; West, R.M.; Gould, I.M.; Harbarth, S.; Nathwani, D. ESCMID Study Group for Antimicrobial Policies (ESGAP); ISC Group on Antimicrobial Stewardship. An international cross-sectional survey of antimicrobial stewardship programmes in hospitals. J. Antimicrob. Chemother. 2015, 70, 1245-1255. [CrossRef] [PubMed]

14. Al-Azzam, S.I.; Alzoubi, K.H.; Mhaidat, N.M.; Haddadin, R.D.; Masadeh, M.M.; Tumah, H.N.; Magableh, A.; Maraqa, N.K. Preoperative antibiotic prophylaxis practice and guideline adherence in Jordan: A multi-centre study in Jordanian hospitals. J. Infect. Dev. Ctries. 2012, 6, 715-720. [CrossRef] [PubMed]

15. Bai, Y.; Wang, S.; Yin, X.; Bai, J.; Gong, Y.; Lu, Z. Factors associated with doctors' knowledge on antibiotic use in China. Sci. Rep. 2016, 6, 23429. [CrossRef] [PubMed]

16. Quet, F.; Vlieghe, E.; Leyer, C.; Buisson, Y.; Newton, P.N.; Naphayvong, P.; Keoluangkhot, V.; Chomarat, M.; Longuet, C.; Steenkeste, N.; et al. Antibiotic prescription behaviours in Lao People's Democratic Republic: A knowledge, attitude and practice survey. Bull. World Health Organ. 2015, 93, 219-227. [CrossRef] [PubMed] 
17. Chandy, S.J.; Mathai, E.; Thomas, K.; Faruqui, A.R.; Holloway, K.; Lundborg, C.S. Antibiotic use and resistance: Perceptions and ethical challenges among doctors, pharmacists and the public in Vellore, South India. Indian J. Med. Ethics 2013, 10, 20-27. [CrossRef]

18. Nga, D.T.T.; Chuc, N.T.K.; Hoa, N.P.; Hoa, N.Q.; Nguyen, N.T.T.; Loan, H.T.; Toan, T.K.; Phuc, H.D.; Horby, P.; Van Yen, N.; et al. Antibiotic sales in rural and urban pharmacies in northern Vietnam: An observational study. BMC Pharmacol. Toxicol. 2014, 15, 6. [CrossRef]

19. Reynolds, L.; Mckee, M. Factors influencing antibiotic prescribing in China: An exploratory analysis. Health Policy 2009, 90, 32-36. [CrossRef]

20. Kotwani, A.; Wattal, C.; Joshi, P.C.; Holloway, K. Irrational use of antibiotics and role of the pharmacist: An insight from a qualitative study in New Delhi, India. J. Clin. Pharm. Ther. 2012, 37, 308-312. [CrossRef]

21. Salim, A.M.A.; Elgizoli, B. Exploring the reasons why pharmacists dispense antibiotics without prescriptions in Khartoum state, Sudan. Int. J. Pharm. Pract. 2017, 25, 59-65. [CrossRef]

22. Dillip, A.; Embrey, M.; Shekalaghe, E.; Ross-Degnan, D.; Vialle-Valentin, C.; Kimatta, S.; Liana, J.; Rutta, E.; Valimba, R.; Chalker, J. What motivates antibiotic dispensing in accredited drug dispensing outlets in Tanzania? A qualitative study. Antimicrob. Resist. Infect. Control 2015, 4, 30. [CrossRef] [PubMed]

23. Akoria, O.A.; Isah, A.O. An evaluation of doctors' prescribing performance in Nigeria. Pak. J. Med. Sci. 2009, 25, 533-538.

24. Giri, B.R.; Shankar, P.R. Learning how drug companies promote medicines in Nepal: An educational initiative looks critically at the drug industry's promotional tactics. PLoS Med. 2005, 2, 0710-0711. [CrossRef] [PubMed]

25. Riaz, H.; Godman, B.; Hussain, S.; Malik, F.; Mahmood, S.; Shami, A.; Bashir, S. Prescribing of bisphosphonates and antibiotics in Pakistan: Challenges and opportunities for the future. J. Pharm. Health Serv. Res. 2015, 6, 111-121. [CrossRef]

26. Hussain, S.; Malik, F.; Hameed, A.; Parveen, G.; Raja, F.Y.; Riaz, H.; Shafaat, S.; Wajid, A.; Channa, R.A. Pharmacoepidemiological studies of prescribing practices of health care providers of Pakistan: A cross sectional survey. Afr. J. Pharm. Pharmacol. 2011, 5, 1484-1493. [CrossRef]

27. Kotwani, A.; Wattal, C.; Katewa, S.; Joshi, P.C.; Holloway, K. Factors influencing primary care physicians to prescribe antibiotics in Delhi India. Fam. Pract. 2010, 27, 684-690. [CrossRef] [PubMed]

28. Tillekeratne, L.G.; Bodinayake, C.K.; Dabrera, T.; Nagahawatte, A.; Arachchi, W.K.; Sooriyaarachchi, A.; Stewart, K.; Watt, M.; Østbye, T.; Woods, C.W. Antibiotic overuse for acute respiratory tract infections in Sri Lanka: A qualitative study of outpatients and their physicians. BMC Fam. Pract. 2017, 18, 37. [CrossRef]

29. Zhang, Z.; Zhan, X.; Zhou, H.; Sun, F.; Zhang, H.; Zwarenstein, M.; Liu, Q.; Li, Y.; Yan, W. Antibiotic prescribing of village doctors for children under 15 years with upper respiratory tract infections in rural China: A qualitative study. Medicine 2016, 95, e3803. [CrossRef]

30. Wasserman, S.; Potgieter, S.; Shoul, E.; Constant, D.; Stewart, A.; Mendelson, M.; Boyles, T.H. South African medical students' perceptions and knowledge about antibiotic resistance and appropriate prescribing: Are we providing adequate training to future prescribers? S. Afr. Med. J. (Suid-Afrikaanse tydskrif vir geneeskunde) 2017, 107, 405-410. [CrossRef]

31. Ahmed, S.M.; Islam, Q.S. Availability and rational use of drugs in primary healthcare facilities following the national drug policy of 1982: Is Bangladesh on right track? J. Health Popul. Nutr. 2012, 30, 99-108. [CrossRef]

32. Kibuule, D.; Mubita, M.; Naikaku, E.; Kalemeera, F.; Godman, B.B.; Sagwa, E. An analysis of policies for cotrimoxazole, amoxicillin and azithromycin use in Namibia's public sector: Findings and therapeutic implications. Int. J. Clin. Pract. 2017, 71, e12918. [CrossRef] [PubMed]

33. Senn, N.; Rarau, P.; Salib, M.; Manong, D.; Siba, P.; Rogerson, S.; Mueller, I.; Genton, B. Use of antibiotics within the IMCI guidelines in outpatient settings in Papua New Guinean children: An observational and effectiveness study. PLoS ONE 2014, 9, e90990. [CrossRef] [PubMed]

34. Biswas, R.; Dineshan, V.; Narasimhamurthy, N.S.; Kasthuri, A.S. Integrating hospital-acquired lessons into community health practice: Optimizing antimicrobial use in Bangalore. J. Contin. Educ. Health Prof. 2007, 27, 105-110. [CrossRef] [PubMed]

35. Kazaura, M.; Lugangira, K.; Kalokola, F. Prescription practices for non-malaria febrile illnesses among under-fives in the Lake Zone, Tanzania. Asian Pac. J. Trop. Dis. 2016, 6, 759-764. [CrossRef] 
36. Pham, D.K.; Chu, J.; Do, N.T.; Brose, F.; Degand, G.; Delahaut, P.; De Pauw, E.; Douny, C.; Nguyen, K.V.; $\mathrm{Vu}$, T.D.; et al. Monitoring Antibiotic Use and Residue in Freshwater Aquaculture for Domestic Use in Vietnam. EcoHealth 2015, 12, 480-489. [CrossRef] [PubMed]

37. Paredes, P.; de la Peña, M.; Flores-Guerra, E.; Diaz, J.; Trostle, J. Factors influencing physicians' prescribing behaviour in the treatment of childhood diarrhoea: Knowledge may not be the clue. Soc. Sci. Med. 1996, 42, 1141-1153. [CrossRef]

38. Himmel, W.; Lippert-Urbanke, E.; Kochen, M.M. Are patients more satisfied when they receive a prescription? The effect of patient expectations in general practice. Scand. J. Prim. Health Care 1997, 15, 118-122. [CrossRef]

39. Coenen, S.; Francis, N.; Kelly, M.; Hood, K.; Nuttall, J. Are Patient Views about Antibiotics Related to Clinician Perceptions, Management and Outcome? A Multi-Country Study in Outpatients with Acute Cough. PLoS ONE 2013, 8, e76691. [CrossRef]

40. Tomson, G.; Vlad, I. The need to look at antibiotic resistance from a health systems perspective. Ups J. Med. Sci. 2014, 119, 117-124. [CrossRef]

41. Hargreaves, T. Practice-ing behaviour change: Applying social practice theory to pro-environmental behaviour change. J. Consum. Cult. 2011, 11, 79-99. [CrossRef]

42. Caldwell, S.E.M.; Mays, N. Studying policy implementation using a macro, meso and micro frame analysis: The case of the Collaboration for Leadership in Applied Health Research \& Care (CLAHRC) programme nationally and in North West London. Health Res. Policy Syst. 2012, 10, 32. [PubMed]

43. Grace, D. Review of Evidence on Antimicrobial Resistance and Animal Agriculture in Developing Countries. 2015. Available online: https:/ /www.gov.uk/dfid-research-outputs/review-of-evidence-on-antimicrobialresistance-and-animal-agriculture-in-developing-countries-201309 (accessed on 20 December 2018).

44. Cross, J.; MacGregor, H. Knowledge, Legitimacy and Economic Practice in Informal Markets for Medicine: A Critical Review of Research. Soc. Sci. Med. 2010, 71, 1593-1600. [CrossRef] [PubMed]

45. Edwards, R.; Charani, E.; Sevdalis, N.; Alexandrou, B. Optimisation of infection prevention and control in acute health care by use of behaviour change: A systematic review. Lancet Infect. Dis. 2012, 12, 318-329. [CrossRef]

46. Bloom, G.; Henson, G.; Peters, D. Innovation in regulation of rapidly changing health markets. Glob. Health 2014, 10, 53. [CrossRef] [PubMed]

47. Hoa, N.Q.; Thi Lan, P.; Phuc, H.D.; Chuc, N.T.K.; Stalsby-Lundborg, C. Antibiotic prescribing and dispensing for acute respiratory infections in children: Effectiveness of a multi-faceted intervention for health-care providers in Vietnam. Glob. Health Action 2017, 10, 1327638. [CrossRef] [PubMed]

48. Nhung, N.T.; Cuong, N.V.; Campbell, J.; Hoa, N.T.; Bryant, J.E.; Truc, V.N.; Kiet, B.T.; Jombart, T.; Trung, N.V.; Hien, V.B.; et al. High levels of antimicrobial resistance among escherichia coli isolates from livestock farms and synanthropic rats and shrews in the Mekong Delta of Vietnam. Appl. Environ. Microbiol. 2015, 81, 812-820. [CrossRef]

49. Liu, Y.Y.; Wang, Y.; Walsh, T.R.; Yi, L.X.; Zhang, R.; Spencer, J.; Doi, Y.; Tian, G.; Dong, B.; Huang, X.; et al. Emergence of plasmid-mediated colistin resistance mechanism MCR-1 in animals and human beings in China: A microbiological and molecular biological study. Lancet Infect. Dis. 2016, 16, 161-168. [CrossRef]

50. Nguyen, N.T.; Nguyen, H.M.; Nguyen, C.V.; Nguyen, T.V.; Nguyen, M.T.; Thai, H.Q.; Mai, H.H.; Thwaites, G.; Ngo, H.T.; Baker, S.; et al. Use of colistin and other critical antimicrobials on pig and chicken farms in southern Vietnam and its association with resistance in commensal Escherichia coli bacteria. Appl. Environ. Microbiol. 2016, 82, 3727-3735. [CrossRef]

51. Holloway, K.A.; Rosella, L.; Henry, D. The Impact of WHO Essential Medicines Policies on Inappropriate Use of Antibiotics. PLoS ONE 2016, 11, e0152020. [CrossRef]

52. Leach, M.; Bett, B.; Said, M.; Bukachi, S.; Sang, R.; Anderson, N.; Machila, N.; Kuleszo, J.; Schaten, K.; Dzingirai, V.; et al. Local disease-Ecosystem-Livelihood dynamics: Reflections from comparative case studies in Africa. Philos. Trans. R. Soc. B Biol. Sci. 2017, 372, 1725. [CrossRef]

53. Liverani, M.; Waage, J.; Barnett, T.; Pfeiffer, D.U.; Rushton, J.; Rudge, J.W.; Loevinsohn, M.E.; Scoones, I.; Smith, R.D.; Cooper, B.S.; et al. Understanding and managing zoonotic risk in the new livestock industries. Environ. Health Perspect. 2013. [CrossRef] [PubMed]

54. Bloom, G.; Standing, H.; Lucas, H.; Bhuiya, A.; Oladepo, O.; Peters, D.H. Making health markets work better for poor people: The case of informal providers. Health Policy Plan. 2011, 26, i45-i52. [CrossRef] [PubMed] 
55. Gautham, M.; Shyamprasad, K.M.; Singh, R.; Zachariah, A.; Singh, R.; Bloom, G. Informal rural healthcare providers in North and South India. Health Policy Plan. 2014, 29, i20-i29. [CrossRef] [PubMed]

56. Zhang, W.; Shen, X.; Wang, Y.; Chen, Y.; Huang, M.; Zeng, Q.; Yang, Y. Antibiotic use in five children's hospitals during 2002-2006: The impact of antibiotic guidelines issued by the Chinese Ministry of Health. Pharmacoepidemiol. Drug Saf. 2008, 17, 306-311. [CrossRef] [PubMed]

57. Ristić, S.; Miljković, B.; Vezmar, S.; Stanojević, D. Are local clinical guidelines useful in promoting rational use of antibiotic prophylaxis in caesarean delivery? Pharm. World Sci. 2010, 32, 139-145. [CrossRef] [PubMed]

58. Liu, C.; Zhang, X.; Wang, X.; Zhang, X.; Wan, J.; Zhong, F. Does public reporting influence antibiotic and injection prescribing to all patients? A cluster-randomized matched-pair trial in china. Medicine 2016, 95, e3965. [CrossRef]

59. Tang, Y.; Liu, C.; Zhang, X. Public reporting as a prescriptions quality improvement measure in primary care settings in China: Variations in effects associated with diagnoses. Sci. Rep. 2016, 6, 39361. [CrossRef]

60. Tang, Y.; Liu, C.; Zhang, X. Performance associated effect variations of public reporting in promoting antibiotic prescribing practice: A cluster randomized-controlled trial in primary healthcare settings. Prim. Health Care Res. Dev. 2017, 18, 482-491. [CrossRef]

61. Yang, L.; Liu, C.; Wang, L.; Yin, X.; Zhang, X. Public reporting improves antibiotic prescribing for upper respiratory tract infections in primary care: A matched-pair cluster-randomized trial in China. Health Res. Policy Syst. 2014, 12, 61. [CrossRef]

62. Santa-Ana-Tellez, Y.; Mantel-Teeuwisse, A.K.; Leufkens, H.G.M.; Wirtz, V.J. Seasonal variation in penicillin use in Mexico and Brazil: Analysis of the impact of over-the-counter restrictions. Antimicrob. Agents Chemother. 2015, 59, 105-110. [CrossRef]

63. Moura, M.L.; Boszczowski, I.; Mortari, N.; Barrozo, L.V.; Chiaravalloti Neto, F.; Lobo, R.D.; Levin, A.S. The Impact of Restricting Over-the-Counter Sales of Antimicrobial Drugs: Preliminary Analysis of National Data. Medicine 2015, 94, e1605. [CrossRef] [PubMed]

64. Minzi, O.; Manyilizu, V. Application of basic pharmacology and dispensing practice of antibiotics in accredited drug-dispensing outlets in Tanzania. Drug Healthc. Patient Saf. 2013, 5, 5-11. [CrossRef] [PubMed]

65. Awad, A.I.; Eltayeb, I.B.; Baraka, O.Z. Changing antibiotics prescribing practices in health centers of Khartoum State, Sudan. Eur. J. Clin. Pharmacol. 2006, 62, 135-142. [CrossRef] [PubMed]

66. Eltayeb, I.B.; Awad, A.I.; Mohamed-Salih, M.S.; Daffa-Alla, M.A.; Ahmed, M.B.; Ogail, M.A.; Matowe, L. Changing the prescribing patterns of sexually transmitted infections in the White Nile Region of Sudan. Sex. Transm. Infect. 2005, 81, 426-427. [CrossRef] [PubMed]

67. Messina, A.P.; van den Bergh, D.; Goff, D.A. Antimicrobial Stewardship with Pharmacist Intervention Improves Timeliness of Antimicrobials Across Thirty-three Hospitals in South Africa. Infect. Dis. Ther. 2015, 4, 5-14. [CrossRef] [PubMed]

68. Shen, J.; Sun, Q.; Zhou, X.; Wei, Y.; Qi, Y.; Zhu, J.; Yan, T. Pharmacist interventions on antibiotic use in inpatients with respiratory tract infections in a Chinese hospital. Int. J. Clin. Pharm. 2011, 33, 929-933. [CrossRef]

69. Apisarnthanarak, A.; Danchaivijitr, S.; Khawcharoenporn, T.; Limsrivilai, J.; Warachan, B.; Bailey, T.C.; Fraser, V.J. Effectiveness of education and an antibiotic-control program in a tertiary care hospital in Thailand. Clin. Infect. Dis. 2006, 42, 768-775. [CrossRef]

70. Bantar, C.; Sartori, B.; Vesco, E.; Heft, C.; Saúl, M.; Salamone, F.; Oliva, M.E. A hospitalwide intervention program to optimize the quality of antibiotic use: Impact on prescribing practice, antibiotic consumption, cost savings, and bacterial resistance. Clin. Infect. Dis. 2003, 37, 180-186. [CrossRef]

71. Kafle, K.K.; Bhuju, G.B.; Karkee, S.B.; Prasad, R.R.; Shrestha, N.; Shrestha, A.D.; Daud, M. An intervention improving prescribing practices and monitoring drugs availability in a district. Nepal Med. Coll. J. NMCJ 2009, 11, 217-221.

72. Opondo, C.; Ayieko, P.; Ntoburi, S.; Wagai, J.; Opiyo, N.; Irimu, G.; English, M. Effect of a multi-faceted quality improvement intervention on inappropriate antibiotic use in children with non-bloody diarrhoea admitted to district hospitals in Kenya. BMC Pediatr. 2011, 11, 109. [CrossRef]

73. Chuc, N.T.K.; Larsson, M.; Do, N.T.; Diwan, V.K.; Tomson, G.B.; Falkenberg, T. Improving private pharmacy practice: A multi-intervention experiment in Hanoi, Vietnam. J. Clin. Epidemiol. 2002, 55, 1148-1155. [CrossRef]

74. Shrestha, N.; Samir, K.; Baltussen, R.; Kafle, K.; Bishai, D.; Niessen, L. Practical approach to lung health in Nepal: Better prescribing and reduction of cost. Trop. Med. Int. Health 2006, 11, 765-772. [CrossRef] [PubMed] 
75. Sun, Q.; Dyar, O.J.; Zhao, L.; Tomson, G.; Nilsson, L.E.; Grape, M.; Lundborg, C.S. Overuse of antibiotics for the common cold-Attitudes and behaviors among doctors in rural areas of Shandong Province, China. BMC Pharmacol. Toxicol. 2015, 16, 6. [CrossRef] [PubMed]

76. Esmaily, H.; Silver, I.; Shiva, S.; Gargani, A.; Maleki-Dizaji, N.; Al-Maniri, A.; Wahlstrom, R. Can rational prescribing be improved by an outcome-based educational approach? A randomized trial completed in Iran. J. Contin. Educ. Health Prof. 2010, 30, 11-18. [CrossRef] [PubMed]

77. Shao, A.F.; Rambaud-Althaus, C.; Samaka, J.; Faustine, A.F.; Perri-Moore, S.; Swai, N.; D'Acremont, V. New Algorithm for Managing Childhood Illness Using Mobile Technology (ALMANACH): A controlled non-inferiority study on clinical outcome and antibiotic use in Tanzania. PLoS ONE 2015, 10, e0132316. [CrossRef] [PubMed]

78. Rambaud-Althaus, C.; Shao, A.; Samaka, J.; Swai, N.; Perri, S.; Kahama-Maro, J.; Genton, B. Performance of Health workers using an Electronic Algorithm for the Management of Childhood Illness in Tanzania: A pilot implementation study. Am. J. Trop. Med. Hyg. 2017, 96, 249-257. [CrossRef]

79. Bhavnani, D.; Phatinawin, L.; Chantra, S.; Olsen, S.J.; Simmerman, J.M. The influence of rapid influenza diagnostic testing on antibiotic prescribing patterns in rural Thailand. Int. J. Infect. Dis. 2007, 11, 355-359. [CrossRef]

80. Yip, W.; Powell-Jackson, T.; Chen, W.; Hu, M.; Fe, E.; Hu, M.; Hsiao, W. Capitation combined with pay-for-performance improves antibiotic prescribing practices in rural China. Health Aff. 2014, 33, 502-510. [CrossRef]

81. Kallel, H.; Abboud, P.; Nkouka, S.; Mahamat, A.; Moreau, B.; Nkont Cho, F.; Saint-Lorant, G.; Djossou, F. Effectiveness of postprescription antibiotic stewardship to reduce carbapenem consumption: A quantitative study. J. Hosp. Infect. 2017, 97, 294-295. [CrossRef]

82. Ma, X.; Xie, J.; Yang, Y.; Guo, F.; Gao, Z.; Shao, H.; Huang, Y.; Yang, C.; Qiu, H. Antimicrobial stewardship of Chinese ministry of health reduces multidrug-resistant organism isolates in critically ill patients: A pre-post study from a single center. BMC Infect. Dis. 2016, 16, 704. [CrossRef]

83. Ozkurt, Z.; Erol, S.; Kadanali, A.; Ertek, M.; Ozden, K.; Tasyaran, M.A. Changes in antibiotic use, cost and consumption after an antibiotic restriction policy applied by infectious disease specialists. Jpn. J. Infect. Dis. 2005, 58, 338-343. [PubMed]

84. Zhang, H.H.; Du, Y.; Liu, W.; Song, S.D.; Zhao, W.; Huang, G.W.; Wang, H.S. Effectiveness of Antibiotic Use Management in Tianjin (2011-2013): A Quasi-Experimental Study. Med. Sci. Monit. Int. Med. J. Exp. Clin. Res. 2017, 23, 725-731. [CrossRef]

85. Marković-Peković, V.; Grubiša, N.; Burger, J.; Bojanić, L.; Godman, B. Initiatives to reduce nonprescription sales and dispensing of antibiotics: Findings and implications. J. Res. Pharm. Pract. 2017, 6, 120-125. [CrossRef] [PubMed]

86. Magedanz, L.; Silliprandi, E.M.; dos Santos, R.P. Impact of the pharmacist on a multidisciplinary team in an antimicrobial stewardship program: A quasi-experimental study. Int. J. Clin. Pharm. 2012, 34, 290-294. [CrossRef] [PubMed]

87. Ding, D.; Pan, Q.; Shan, L.; Liu, C.; Gao, L.; Hao, Y.; Liu, G. Prescribing patterns in outpatient clinics of township hospitals in China: A comparative study before and after the 2009 health system reform. Int. J. Environ. Res. Public Health 2016, 13, 679. [CrossRef] [PubMed]

88. Wei, X.; Yin, J.; Walley, J.D.; Zhang, Z.; Hicks, J.P.; Zhou, Y.; Sun, Q.; Zeng, J.; Lin, M. Impact of China's essential medicines scheme and zero-mark-up policy on antibiotic prescriptions in county hospitals: A mixed methods study. Trop. Med. Int. Health 2017, 22, 1166-1174. [CrossRef] [PubMed]

89. Song, Y.; Bian, Y.; Petzold, M.; Li, L.; Yin, A. The impact of China's national essential medicine system on improving rational drug use in primary health care facilities: An empirical study in four provinces. BMC Health Serv. Res. 2014, 14, 507. [CrossRef]

90. Yao, Q.; Liu, C.; Ferrier, J.A.; Liu, Z.; Sun, J. Urban-rural inequality regarding drug prescriptions in primary care facilities-A pre-post comparison of the National Essential Medicines Scheme of China. Int. J. Equity Health 2015, 14, 58. [CrossRef]

91. Yang, L.; Liu, C.; Ferrier, J.A.; Zhou, W.; Zhang, X. The impact of the National Essential Medicines Policy on prescribing behaviours in primary care facilities in Hubei province of China. Health Policy Plan. 2013, 28, 750-760. [CrossRef] 
92. Uzochukwu, B.S.C.; Onwujekwe, O.E.; Akpala, C.O. Effect of the Bamako-Initiative drug revolving fund on availability and rational use of essential drugs in primary health care facilities in south-east Nigeria. Health Policy Plan. 2002, 17, 378-383. [CrossRef]

93. Sun, X.; Jackson, S.; Carmichael, G.A.; Sleigh, A.C. Prescribing behaviour of village doctors under China's New Cooperative Medical Scheme. Soc. Sci. Med. 2009, 68, 1775-1779. [CrossRef] [PubMed]

94. Holloway, K.A.; Karkee, S.; Tamang, A.; Gurung, Y.B.; Pradhan, R.; Reeves, B.C. The effect of user fees on prescribing quality in rural Nepal: Two controlled pre-post studies to compare a fee per drug unit vs. a fee per drug item. Trop. Med. Int. Health 2009, 13, 541-547. [CrossRef] [PubMed]

95. Johansson, E.W.; Selling, K.E.; Nsona, H.; Mappin, B.; Gething, P.W.; Petzold, M.; Peterson, S.S.; Hildenwall, H. Integrated paediatric fever management and antibiotic over-treatment in Malawi health facilities: Data mining a national facility census. Malar. J. 2016, 15, 396. [CrossRef] [PubMed]

96. Potharaju, H.R.; Kabra, S.G. Prescription audit of outpatient attendees of secondary level government hospitals in Maharashtra. Indian J. Pharmacol. 2011, 43, 150-156. [CrossRef] [PubMed]

97. Ravi, N.; Laha, A.; Hmar, L.; Chatterjee, S.; Goswami, J.; Goel, G.; Dhar, K.; Ghosh, T.; Chatterjee, S.; Datta, S.S.; et al. Exploring the prescribing behaviours and the mind of antibiotic prescribers is critical for a successful antibiotic stewardship programme: Results of a survey from Eastern India. Indian J. Med. Microbiol. 2017, 35, 299-301. [PubMed]

98. Zaidi, M.B.; Dreser, A.; Figueroa, I.M. A collaborative initiative for the containment of antimicrobial resistance in Mexico. Zoonoses Public Health 2015, 62, 52-57. [CrossRef] [PubMed]

99. Embrey, M.; Vialle-Valentin, C.; Dillip, A.; Kihiyo, B.; Mbwasi, R.; Semali, I.A.; Chalker, J.C.; Liana, J.; Lieber, R.; Johnson, K.; et al. Understanding the Role of Accredited Drug Dispensing Outlets in Tanzania's Health System. PLoS ONE 2016, 11, e0164332. [CrossRef]

100. Shao, A.F.; Rambaud-Althaus, C.; Swai, N.; Kahama-Maro, J.; Genton, B.; D'acremont, V.; Pfeiffer, C. Can smartphones and tablets improve the management of childhood illness in Tanzania? A qualitative study from a primary health care worker's perspective. BMC Health Serv. Res. 2015, 15, 135. [CrossRef]

101. Saengcharoen, W.; Chongsuvivatwong, V.; Lerkiatbundit, S.; Wongpoowarak, P. Factors influencing dispensing of antibiotics for upper respiratory infections among Southern Thai community pharmacists. J. Clin. Pharm. Ther. 2008, 33, 123-129. [CrossRef]

102. Karabay, O.; Hoşoğlu, S.; Güçlü, E.; Akalin, Ş.; Altay, F.A.; Aydin, E.; Ceylan, B.; Çelik, A.; Çelik, İ.; Demirdal, T.; et al. Impact of antimicrobial drug restrictions on doctors' behaviors. Turk. J. Med. Sci. 2016, 46, 133-138. [CrossRef]

103. Ozgenç, O.; Genç, V.E.; Ari, A.A.; Sibel, E.; Saçar, S.; Ozunlu, H.; Akgul, A.; Demirturk, N.; Cetin, C.B.; Sungur, M.; et al. Evaluation of the therapeutic use of antibiotics in Aegean Region hospitals of Turkey: A multicentric study. Indian J. Med. Microbiol. 2011, 29, 124-129. [CrossRef] [PubMed] 